\title{
APONTAMENTOS ACERCA DA TIPOLOGIA DOS PARTIDOS POLÍTICOS NO BRASIL
}

\author{
NOTES ABOUT THE TYPOLOGY OF POLITICAL PARTIES IN BRAZIL
}

\author{
Leandro Mello Frota \\ Doutorando em Ciência, Tecnologia e Inovação em Agropecuária pela UFRRJ. \\ Mestre em Ciência Política e Relações Internacionais pelo IUPERJ. \\ Professor da EMERJ. \\ E-mail: leandro.mellofrota@gmail.com

\begin{abstract}
Rogerio Borba
Doutor em Sociologia pelo IUPERJ. Mestre em Direito pela FDC. Professor do PPGD da Universidade Veiga de Almeida. E-mail: rogerioborba@gmail.com
\end{abstract}

RESUMO: Este artigo aborda o papel dos partidos políticos na democracia contemporânea. Parte-se da constatação de que os partidos são necessários e imprescindíveis para o melhor funcionamento da democracia. Propõe-se relacionar com o tema partidos políticos nas democracias contemporâneas, sendo abordadas as classificações dos partidos, fazendo apontamentos a respeito dos partidos de quadros, massas, catch-all e cartel. O artigo se insere no ramo das Ciências Jurídicas e Políticas, na área do Direito Eleitoral, sendo analisada em uma perspectiva holística. A metodologia adotada foi a bibliográfica e documental.

PALAVRAS-CHAVE: Direito Eleitoral; Partidos Políticos; Tipologia Partidária.

ABSTRACT: This article addresses the role of political parties in contemporary democracy. It starts from the realization that parties are necessary and indispensable for the better functioning of democracy. It proposes to relate to the theme of political parties in contemporary democracies, addressing the classifications of the parties, making notes regarding the parties of cadres, masses, catch-all and cartel. The article is part of the branch of Legal and Political Sciences, in the area of Electoral Law, being analyzed in a holistic perspective. The methodology adopted was bibliographic and documentary.

KEYWORDS: Electoral Law; Political Parties; Party typology.

\section{INTRODUÇÃO}

Os partidos políticos são o canal de participação política, único meio pelo qual a cidadania pode ser realizada de forma ativa, por meio de candidaturas As transformações que os partidos políticos sofreram ao longo das décadas criaram a falsa sensação de que todos os partidos são a mesma coisa, razão pela qual muitos defendem a sua inutilidade e, consequentemente, a sua extinção. 
Apresenta-se, então o seguinte questionamento: Partido Político é a mesma coisa? A hipótese trabalhada reconhece as diferenças estruturais e finalísticas dos partidos políticos. Objetiva-se, com isso, demonstrar que os partidos não são todos iguais, mesmo que apenas de forma técnica ou estrutural. A metodologia adotada foi a bibliográfica e documental.

A relevância acadêmica da pesquisa se demonstra no sentido de contribuir para a compreensão dos partidos políticos no Brasil, em especial as suas diferenças e estruturas. $\mathrm{O}$ artigo se insere no ramo das Ciências Jurídicas e Políticas, na área do Direito Eleitoral, sendo analisada em uma perspectiva holística.

O trabalho apresenta as muitas divisões dos partidos políticos. A literatura ensina que os partidos são divididos em partidos de massa, aqueles partidos com uma grande penetração na classe média e nas classes trabalhadoras; partidos de quadros ou elites, os partidos personalistas, com poucos filiados e voltados para o prestígio pessoal e não para o coletivo; partidos catchall, os partidos centristas, com atuação partidária ampla e com pouco aspecto ideológico, e os partidos cartel, aqueles mais dependentes do Estado e menos dependente da sociedade.

\section{CONCEITO E TIPOLOGIA DE PARTIDOS POLÍTICOS}

Historicamente, a primeira definição de partido foi dada pelo inglês Edmund Burke. De acordo com esse parlamentar, partido é um grupo de homens unidos para a promoção, pelo seu esforço conjunto, do interesse nacional com base em algum princípio com qual todos concordam. Ainda Sartori (1982) argumenta que Bolingbroke justifica o "partido" apenas como oposição (quando necessária) do país ao soberano inconstitucional.

Ao refletir sobre o conceito do termo partido, pode-se observar definições semelhantes mencionadas por diferentes autores ou fontes. De acordo com o Tribunal Superior Eleitoral (TSE),

partido político é um grupo social de relevante amplitude destinado à arregimentação coletiva, em torno de ideias e de interesses, para levar seus membros a compartilharem do poder decisório nas instâncias governativas. O partido político é uma pessoa jurídica de direito privado, cujo estatuto deve ser registrado na Justiça Eleitoral. (BRASIL, 2020)

Sartori (1982) entende que um partido consiste em qualquer grupo político identificado por um rótulo oficial que se apresente em eleições, e seja capaz de colocar através delas (livres ou não), candidatos a cargos públicos. Para Weber (2003, p. 51) define-se partido político como:

[...] um número relativamente pequeno de homens interessados pela vida política, isto é, para participar do poder, escolhe adeptos, apresenta-se ou apresenta seus protegidos como candidatos a cargos eletivos, reúne os recursos financeiros exigidos e põe-se à rua à procura de votos. 
Ao analisar os dois autores supracitados, Dallagnol (2006) destaca que a importância dos partidos políticos na composição da democracia representativa está na coordenação da participação popular, na conferência de inteligibilidade ao processo eleitoral, na ordenação da competição dos grupos pelo poder e na estimulação da negociação política e da construção de consensos. Sintetizando os conceitos de Weber e Sartori, partidos políticos são definidos como reunião de pessoas que partilham de algum ideal comum e apoiam-se por uma base que se une a esse grupo por meio da semelhança de suas prioridades.

Seguindo o pensamento atribuído ao Professor Lauro Campos da Universidade de Brasília, ao fazer referência ao Espectro ideológico, comentando o livro "História do Pensamento Econômico", partido político consiste em um grupo organizado de pessoas que formam legalmente uma entidade, constituídos com base em formas voluntárias de participação.

Diferentes sociólogos e cientistas políticos estudaram e teorizaram os partidos políticos, sendo Ostrogorsky, Robert Michels, Maurice Duverger, Max Weber, Giovanni Sartori, e Nildo Viana merecedores de grandes destaques.

A diferença entre Michels e Nildo Viana está no fato de que Michels, influenciado por Weber (2003), considera que o predomínio da burocracia nos partidos políticos, especialmente nos partidos fascistas, nazistas, socialistas e comunistas, ocorre por uma necessidade técnica. Em Nildo Viana, a burocratização dos partidos é derivada de um complexo processo social e político que dá origem a expansão de uma nova classe social, a "burocracia".

Assim, Nildo Viana e Robert Michels coincidem em afirmar que a burocracia partidária é uma fração daquela nova classe social: a "burocracia". Essa burocracia partidária, frequentemente ultrapassa a sua função de assessoria do político e passa a ditar regras nos partidos políticos.

\section{PARTIDOS POLÍTICOS NO BRASIL}

Ao analisar a conceituação de partido, observa-se certa incoerência com relação a algumas formas de organização partidária mundial. Anteriormente, foi exposto que partido tem origem em partes. Dessa forma, não faz sentido a existência do Partido Único, em que, quando só um partido é aceito pela legislação do país. Um exemplo de "partido único" é o Partido Comunista Cubano (PCC), porém em Cuba não há necessidade de estar em algum partido político para se eleger.

Outra forma organizacional partidária, adotada em diversos países, tais como no Brasil é o chamado de Pluripartidarismo. Nesse caso, há a existência de vários partidos políticos. Diferentemente, a fim de orientar, a palavra "pluripartidarismo" significa, de fato, pluralidade de partidário. A atual constituição brasileira garante ampla liberdade partidária, mas, na prática, estão impossibilitados de se legalizarem os partidos fascistas, nazistas e monarquistas.

Em muitos países, partidos políticos que não são aceitos legalmente, continuam existindo de maneira informal e clandestinamente, esperando uma reviravolta na política para se legalizarem, o que lhes permitiriam participar de eleições. 
No Brasil, o Partido Conservador e o Partido Liberal foram os primeiros partidos políticos brasileiros com existência legal com surgimento durante o segundo reinado (1840-1889).

Posteriormente, durante a República Velha (1889-1930), os partidos políticos eram organizações regionais, existindo um Partido Republicano em cada estado, cada um tendo estatutos e direções próprias.

Na ditadura civil militar implementou o bipartidarismo no Brasil. Assim, de 1966 até 1979, existiram só a Aliança Renovadora Nacional (ARENA) e o MDB, Movimento Democrático Brasileiro. Em 2014, foram 34 os partidos políticos oficializados e registrados no Tribunal Superior Eleitoral. (Brasil, 2020)

\section{TIPOLOGIA DE PARTIDOS POLÍTICOS}

Existem diversas formas de tipologia de partidos políticos, podendo ser classificados como em função de suas caraterísticas organizacionais, eleitorais ou outras dependendo do olhar do pesquisador. Assim, será adotado a discussão em torno de quatro tipologias partidárias (quadros, massas, catch-all, cartel), bem como um comparativo entre elas, discutindo suas semelhanças e diferenças.

\subsection{PARTIDO DE QUADROS}

Partidos de Quadros ou de Elites, tem característica de partidos voltados para a individualidade do filiado. Em termos programáticos não são ideológicos e sim pragmáticos. Koole (1996) ensina que os Partidos de Quadros modernos têm baixas porcentagens de filiação; estes partidos são um instrumento para os membros ativos da organização. Estes partidos não têm ambições de hegemonia e são colaborativos com outros partidos no parlamento (GUNTHER \& DIAMOND, 2003).

Em confronto com a explicação sobre Partidos de Quadros e as características dos partidos políticos oficializados, pode-se mencionar, através de uma análise, que PSDB, PDT, DEM, PSB, PV E PPS se enquadram nessa tipologia. Desses partidos, observa-se grandes transformações desde sua criação; como exemplo cita-se o PSDB. Esse partido, fundado em 1988, surgiu com o descontentamento de parlamentares dissidentes do PMDB devido ao seu rumo político.

Vale ressaltar que desde os primórdios PMDB segue a tipologia Catch-All, sendo considerado hoje em dia como um dos mais representativos. O agravante, em especial, se deu com a elaboração da Constituição de 1988, com a formação do chamado Centrão, articulação de centro-direita contrária à aprovação de medidas progressistas na Carta Magna. Afirma o deputado federal Sebastião Madeira, presidente do Instituto Teotônio Vilela, em entrevista, que “O PMDB era um partido com projetos regionais, um partido de caciques sem uma orientação nacional. Os políticos que saíram para fundar o PSDB não concordavam com a falta de uma proposta nacional”. (FIORI, 2006) 
Seguindo as premissas do Partido de Quadros, a organização do referido partido político, estruturou-se em focar a candidatura do senador Mário Covas à Presidência da República, colocando-o como a figura central, por meio da priorização de suas qualidades principais e não do partido como um todo em si, diferentemente ao que ocorre com os conceitos Catch-All.

De acordo com o líder do PSDB na Câmara dos Deputados, Jutahy Magalhães Jr. (BA), em 1988, o PSDB:

\footnotetext{
"Era um partido congressual, que não tinha bases nos estados, mas era direcionado em função das figuras", observa. "Era um partido de quadros que tinha presença em alguns estados como São Paulo, Minas, Paraná e Ceará. A partir da campanha do Covas, o partido enraizou-se em todo o Brasil”, acrescenta. (FIORI, 2006)
}

O mesmo comportamento foi observado com as seguintes eleições de Fernando Henrique Cardoso “O Pai do Plano Real”, em 1994/1998; José Serra “O Pai dos Genéricos”, em 2002/2010; Geraldo Alckmin “Grande Administrador de São Paulo", em 2006; e por fim Aécio Neves "Neto do Tancredo Neves", em 2010.

Outro partido que se enquadra como Partido de Quadro é o PSB, porém atualmente passa por um processo de "esquizofrenia partidária", o que dificulta seu enquadramento nas tipologias citadas. Essa fase de transição inicia-se com o falecimento do grande líder político da esquerda e ex-governador de Pernambuco Miguel Arraes, seguido, pelo abrupto falecimento de seu candidato presidencial, Eduardo Campos, no curso das eleições do ano de 2014.

\subsection{PARTIDO DE MASSAS}

O Partido de Massas surgiu da mobilização política da classe operaria na Europa. Os partidos que enquadram nessa tipologia são caracterizados por serem ideológicos, grande quantidade de filiados e apoiadores, mobilizados política da classe média e trabalhadora, ativos em períodos não eleitorais. Os partidos de massa estão inseridos em diversos setores sociais, com forte apoio dos sindicatos e de organizações sociais, o que contribui para o aumento de filiados e bem como para o apoio de seus objetivos na arena parlamentar e social (KATZ \& MAIR, 1995; GUNTHER \& DIAMOND, 2003; GUNTHER, 2005).

Segundo Manin (1995), a organização dos partidos de massa e suas relações com seu eleitorado não conduz ao direcionamento a um candidato, como o que ocorre nos Partidos de Quadros, e sim ao coletivo. Outras diferenças que podem ser apontadas são a estruturação do voto popular, integração e mobilização da massa e cidadãos, na agregação de diversos interesses, no recrutamento de líderes para cargos públicos e na formulação de políticas públicas.

De acordo com Kinzo (2010), a imagem do PT está associada a uma marca capaz de mobilizar o eleitorado facilmente reconhecida, sendo seu diferencial a estrutura organizacional e estratégia oposicionista. Dessa forma, pode-se dizer que o PT tem preferência popular muito 
superior aos outros partidos (MACHADO; PULS, 2010). Esse fato é confirmado pelo cientista político da USP André Singer (2012) em seu livro sobre o lulismo.

Ainda sobre a preferência partidária, Andréa Freitas, cientista política do CEBRAP, afirma que "A preferência partidária pode ser considerada um indicativo forte de intenção de voto, ainda mais quando se trata de um partido que se organizou de baixo para cima" (MACHADO; PULS, 2010). Cita-se como partidos de massas o PT, PCdoB, PSOL, PSTU, PCB, PCO, sendo os três últimos sem representação parlamentar.

Dos partidos supracitados anteriormente, destaca-se o Partido dos Trabalhadores por ser o de maior representação política e estar a 12 anos governando. A formação do PT, primeiro grande partido de massa, ocorre com o advento do pluripartidarismo em 1979, época em que estava instaurada o regime civil militar. Esse partido foi fundado com o objetivo de representar as classes da sociedade com pouca representatividade na arena política, no caso os trabalhadores, operários, membros de movimentos populares e sociais.

Além desses, houve a participação de grupos tradicionalmente incompatíveis, da esquerda trotskista à esquerda leninista, marxistas e católicos da Igreja de Libertação e intelectuais de prestígio.

\subsection{PARTIDO CATCH-ALL}

O partido catch-all, teorizado por Otto Kirchheimer, surgiu no pós segunda guerra mundial. Esse modelo de partido concentra-se no cenário eleitoral e não na doutrinação intelectual das massas, visto que não são partidos ideológicos, ou com uma certa frouxidão ideológica (KROUWEL, 2003). Os partidos catch-all são moderados, pragmáticos, ecléticos na orientação políticas, com vários grupos de apoio, como forma de agregar mais interesses na busca pelo voto. O partido não impõe barreiras a sua associação, é aberto a todos, independentemente da matize ideológica, entre seus filiados encontram-se várias orientações políticas. Falta-lhe uma ideologia explícita (GUNTHER \& DIAMOND, 2003). No Brasil, pode-se citar o caso do PMDB, o maior partido catch-all, e o PSD, partido descrito por seu presidente como não sendo "nem de direita e nem de esquerda".

Segundo Otto Kirchheimer, como explicado por Melo (2013), as características dos partidos catch-all são:

a) a redução acentuada da ideologia no partido;

b) o reforço da liderança de topo;

c) a diminuição do papel do militante individual no partido;

d) a redução da importância concedida a uma classe social de referência ou a uma clientela religiosa específica; e

e) a abertura a diversos grupos de interesses.

A tipologia catch-all está ligada ao enfraquecimento dos partidos de massas. Esse processo de enfraquecimento para Panebianco (2005) se deu a partir de cinco etapas, são elas: 
1) Perda ideológica: com as campanhas centrando em temas gerais;

2) Maior influência dos grupos de interesse sobre o partido;

3) Diminuição do papel representativo e aumento dos aspectos processuais;

4) Fortalecimento do poder dos líderes partidários; e

5) Enfraquecimento dos laços com o eleitorado.

Citam-se como partidos catch-all o PMDB, PSD, PP, PTB e outros partidos menores. Dos partidos citados anteriormente, destaca-se o PMDB e o PSD. O primeiro nasceu da luta pela liberdade e consequentemente a defesa do fim da ditadura civil-militar. Com a redemocratização brasileira e a vitória de Tancredo Neves o PMDB passou a ser o grande fiador da governabilidade no que os especialistas chamam de presidencialismo de coalizão.

Em contradição ao exposto anteriormente, Dallagnol (2006) infere sobre a migração tipológica do PT de partido de massa para Catch-All. Segundo essa autora, desde sua fundação o PT vive por transformações profundas, em que ao longo de mais de 25 anos de trajetória política chega à disputa eleitoral para a Presidência da República de 2002 como um partido catch-all. Ainda de acordo com essa autora, esta modificação se dá pelo fato da diminuição da tendência classista e o aumento da tendência universalista, sendo vista por meio da análise das Resoluções dos Encontros Nacionais do PT nos anos de 1989, 1994, 1998 e 2001 e também das imagens da campanha eleitoral do PT exibidas na televisão em 2002. Imagens essas que apresentam a união de vários aspectos da mudança vivida pelo partido, a modificação em seu discurso e as estratégias de marketing político utilizadas.

O mesmo comportamento pode ser observado em campanhas subsequentes. Em 2014, o foco principal do discurso, marketing eleitoral e político, bem como das novas tecnologias da comunicação (redes sociais) ao invés de ser no partido como um todo, entra em detrimento da militância e das bandeiras do partido, adotando um discurso não ideológico. Um exemplo nítido observado é o desaparecimento do símbolo principal do PT (estrela vermelha) e a cor vermelha nos jingles e propaganda política dos candidatos vinculados ao PT.

Um caso notório foi o candidato a governador do PT por Minas Gerais, Fernando Pimentel, ao ocultar os principais líderes do partido, modificou as cores do material visual e gráfico de vermelho para azul e verde, aproximando do PSDB, e por fim a fraca exposição da estrela símbolo do PT. Esse rumo político que vem sendo traçado pelo PT foi um dos fatores que, em 2004, militantes de esquerda insatisfeitos formaram o Partido Socialismo e Liberdade.

\subsection{PARTIDOS CARTEL}

Em oposição a tese apresentada por estudiosos, especialmente na Europa Ocidental na década de 90, de que os partidos políticos estavam em declínio, os autores Katz e Mair (1995) propuseram existência de um novo modelo de partido nas democracias contemporâneas. Esse modelo denominado Partido Cartel, consiste no resultado de uma linha evolutiva caracterizada pelos modelos de partido de quadros, massas e catch-all. Nos partidos do modelo de Katz e Mair, 
o privilegiado é o indivíduo, diferentemente dos partidos de massa e catch-all. Nos partidos de massa, há forte atividade de recrutamento e noção de que os filiados consistiriam em um corpo razoavelmente uníssono, enquanto, nos partidos catch-all, a filiação é encorajada a todos com compromisso dos membros de estratos mais baixos em promover uma militância ativa (ANDREIS, 2008).

De acordo com esses autores, o partido cartel pode ser representado pelo arranjo tripartite (Figura 1), em que há distanciamento da sociedade cível e a proximidade com o Estado, agindo como um intermediário entre a sociedade civil e o Estado.

Figura 1 - Arranjo tripartite entre sociedade civil, Estado e partido político, segundo Katz e Mair.
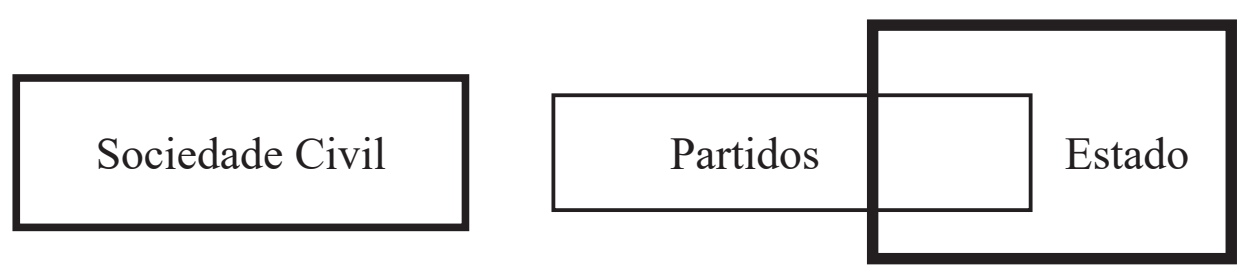

Fonte: Katz e Mair (1994)

Assim, segundo Amaral (2013), partido cartel é definido por suas relações com o Estado, apontadas como essenciais para a aquisição de recursos necessários para a sobrevivência da organização. De acordo com Mair (1994), os principais indicadores dessa relação são:

a) A garantia de acesso a meios de comunicação de massa, especialmente à televisão, proporcionada pelo Estado por meio de regulamentação ou cessão direta em canais estatais para a comunicação com o eleitorado;

b) O Estado é um importante mantenedor dos recursos humanos à disposição dos partidos. Assessores de parlamentares e membros do Executivo são pagos com recursos estatais e os funcionários do partido são mantidos, em grande medida, graças a repasses financeiros provenientes do Estado;

c) A atividade e a organização partidárias são cada vez mais moldadas a partir da regulamentação estabelecida pelo Estado;

d) O Estado confere legitimidade aos partidos políticos perante a sociedade civil quando estes ocupam cargos públicos; e

e) Os partidos utilizam recursos estatais para a distribuição de incentivos seletivos a seus membros ou grupos sociais que os apoiam (patronagem partidária).

Os Partidos de Cartel surgem a partir de 1950, mas destacam-se a partir dos anos 70 na Europa. Com relação ao Brasil, diversos autores se questionam sobre a ocorrência de um processo de cartelização dos partidos. Segundo Ribeiro (2013), os principais fatores que sugerem a possibilidade de cartelização política brasileira são a agência estatal corresponde, a hegemonia da face pública no Executivo nacional, a estabilização da competição, distâncias mais curtas ideológicas, evidências de conluio entre os principais partidos (superando clivagens governo / oposição e esquerda / direita) para promover objetivos comuns, a perspectiva de todas as partes 
médias e grandes para integrar o governo e reduzindo a distância entre vencedores e perdedores em termos de acesso a recursos do Estado.

Nicolau (2010) especulou sobre essa possibilidade para o Brasil, ressaltando a baixa intensidade de partidos ideológicos, a possibilidade de envolvimento de todas as forças relevantes no governo federal e à dependência considerável em relação aos recursos e Regulamentos do Estado. Já Alcántara Sáez (2004) sugere esta hipótese para a América Latina como resultado da consolidação democrática. No entanto, Ribeiro (2013) ao analisar o sistema partidário atual no Brasil sob a ótica conceitual dos autores Katz e Mair, afirmou que nas condições atuais brasileiras, é pouco provável a formação de um cartel fechado e estável. Ainda segundo o autor, um possível processo de cartelização só poderia assumir a forma de um "cartel dinâmico", ou seja, com rotatividade entre os quatro ou cinco, incluindo o PSD, maiores partidos eleitorais.

\section{CONCLUSÃO}

Os Partidos Políticos nasceram como forma de intermediar as demandas da sociedade com o Estado. Etimologicamente, o termo partido é passado do verbo "partir", tendo desse modo o sentido de dividir. No entanto, por extensão de sentido político, partido significa parte da sociedade representada por um grupo, legalmente formado e orientado para influenciar ou ocupar o poder.

Como visto, há diversas formas de tipologia de partidos políticos, sendo classificados em função de suas caraterísticas organizacionais, eleitorais etc. Foi realizada a discussão em torno de quatro tipologias partidárias, quadros, massas, catch-all, cartel, promovendo-se uma comparação entre elas, discutindo suas semelhanças e diferenças.

Conclui-se que os partidos políticos, embora muitas vezes percebidos pela sociedade como iguais, são diferentes em diversos aspectos técnicos, que servem para o correto exercício da cidadania como instrumento de escolha consciente de um deles para a participação política ativa.

\section{REFERÊNCIAS}

ALCÁNTARA SÁEZ, M. ¿Instituciones o máquinas ideológicas? Origen, programa y organización de los partidos políticos latinoamericanos. Barcelona: ICPS, 2004.

AMARAL, O. E. do. O que sabemos sobre a organização dos partidos políticos: uma avaliação de 100 anos de literatura. Revista Debates, Porto Alegre, v. 7, n. 2, p. 11-32, 2013.

ANDREIS, T. F. A tese do partido-cartel: revisitando o debate. In: Seminário Internacional Organizações e Sociedade: Inovações e Transformações Contemporâneas. 3. Anais [...]. Porto Alegre, [s.n.], 2008.

BRASIL. Tribunal Superior Eleitoral. Glossário eleitoral. Disponível em: http://www.tse.jus. br/eleitor/glossario/termos-iniciados-com-a-letra-p. Acesso em 28 jan. 2020. 
BRASIL. Tribunal Superior Eleitoral. Partidos Políticos registrados no TSE. Disponível em: http://www.tse.jus.br/partidos/partidos-politicos/registrados-no-tse. Acesso em: 28 jan. 2020.

CAMPOS, L. A crise completa a economia política do não. São Paulo: Boitempo. 2001. 346 p.

DALLAGNOL, R. As mudanças no PT: a transformação de um partido de massas em um partido catch-all. Dissertação (Mestrado em Sociologia) - Faculdade de Ciências Humanas e Filosofia, Universidade Federal de Goiás. Goiânia, 2006.

DUVERGER, M. Os partidos políticos. Rio de Janeiro: Zahar, 1980.

FIORI, Mylena. PSDB foi fundado em 1988, por parlamentares dissidentes do PMDB. Agência Brasil [Eleições 2006], 11 jun. 2006. Disponível em: http://memoria.ebc.com. br/agenciabrasil/noticia/2006-06-11/eleicoes-2006-psdb-foi-fundado-em-1988-porparlamentares-dissidentes-do-pmdb. Acesso em: 28 jan. 2020.

GUNTHER, R. Parties and electoral behavior in Southern Europe. Comparative Politics, New York, v. 37, n. 3, p. 253-275, 2005.

GUNTHER, R.; DIAMOND, L. Species of political parties. Party Politics, London, v. 9, n. 2, p. 167-199, 2003.

KATZ, R.; MAIR, P. Changing models of party organization and party democracy. The Emergence of the Cartel Party. Party Politics, London, v. 1, n. 1, p. 5-28, 1995.

KOOLE, Ruud. Cadre, Catch-all or Cartel "A comment on the notion of the cartel party". Party Politics, London, v. 2, n. 4, p. 507-523.

KROUWEL, A. Otto Kirchheimer and the catch-all party. West European Politics, London, v. 2, n. 26, p. 23-40, 2003.

MACHADO, Uirá; PULS, Mauricio. Organização de massas explica popularidade do PT, dizem especialistas. Folha de São Paulo [Eleições 2010], 2 ago. 2010. Disponível em: https:// www1.folha.uol.com.br/poder/776148-organizacao-de-massas-explica-popularidade-do-ptdizem-especialistas.shtml. Acesso em: 28 jan. 2020.

MANIN, Bernard. As Metamorfoses do Governo Representativo. Revista Brasileira de Ciências Sociais, São Paulo, n. 29, 1995.

MELO, P. V. T. P. de. O PMDB e a sua manutenção no centro do jogo político: de catch all a cartel. Dissertação (Mestrado em Ciência Política) - Faculdade de Filosofia e Ciências Humanas, Universidade Federal de Minas Gerais, 2013.

MICHELS, R. Sociologia dos Partidos Políticos. Brasília: UnB, 1982.

NICOLAU, J. Democracy in Brazil, 1985-2006: Moving toward Cartelization. In:

LAWSON, K.; LANZARO, J. (ed.). Political Parties and Democracy. Santa Barbara: The Americas, 2010. v. 1, cap. 5, p. 101-126.

PANEBIANCO, A. Modelos de partido: organização e poder nos partidos políticos. São Paulo: Martins Fontes, 2005. 
RIBEIRO, P. E. El modelo de partido cartel y el sistema de partidos de Brasil. Revista de Ciência Política, Santiago, v. 33, n. 3, p. 607-629, 2013.

SARTORI, G. Partidos e sistemas partidários. Rio de Janeiro: Zahar, 1982.

SINGER, A. Os sentidos do lulismo: Reforma gradual e pacto conservador. São Paulo: Companhia das Letras, 2012.

VIANA, N. O que são Partidos Políticos. Goiânia: Germinal, 2003.

WEBER, M. Ciência e Política: duas vocações. São Paulo: Cultrix, 2004. 